\title{
Interim Guidance for Interpretation of Zika Virus Antibody Test Results
}

\author{
Ingrid B. Rabe, $\mathrm{MBChB}^{1}$; J. Erin Staples, $\mathrm{MD}, \mathrm{PhD}^{1}$; Julie Villanueva, $\mathrm{PhD}^{1}$; Kimberly B. Hummel, $\mathrm{PhD}^{1}$; Jeffrey A. Johnson, PhD ${ }^{1}$; \\ Laura Rose, MTS ${ }^{1}$; Susan Hills, MBBS ${ }^{1}$; Annemarie Wasley, ScD ${ }^{1}$; Marc Fischer, MD ${ }^{1}$; Ann M. Powers, PhD $^{1}$
}

\section{On May 31, 2016, this report was posted as an MMWR Early Release on the MMWR website (http://www.cdc.gov/mmwr).}

Zika virus is a single-stranded RNA virus in the genus Flavivirus and is closely related to dengue, West Nile, Japanese encephalitis, and yellow fever viruses $(1,2)$. Among flaviviruses, Zika and dengue virus share similar symptoms of infection, transmission cycles, and geographic distribution. Diagnostic testing for Zika virus infection can be accomplished using both molecular and serologic methods. For persons with suspected Zika virus disease, a positive real-time reverse transcriptionpolymerase chain reaction (rRT-PCR) result confirms Zika virus infection, but a negative rRT-PCR result does not exclude infection (3-7). In these cases, immunoglobulin (Ig) $\mathrm{M}$ and neutralizing antibody testing can identify additional recent Zika virus infections $(6,7)$. However, Zika virus antibody test results can be difficult to interpret because of cross-reactivity with other flaviviruses, which can preclude identification of the specific infecting virus, especially when the person previously was infected with or vaccinated against a related flavivirus (8). This is important because the results of Zika and dengue virus testing will guide clinical management. Pregnant women with laboratory evidence of Zika virus infection should be evaluated and managed for possible adverse pregnancy outcomes and be reported to the U.S. Zika Pregnancy Registry or the Puerto Rico Zika Active Pregnancy Surveillance System for clinical follow-up $(9,10)$. All patients with clinically suspected dengue should have proper management to reduce the risk for hemorrhage and shock (11). If serologic testing indicates recent flavivirus infection that could be caused by either Zika or dengue virus, patients should be clinically managed for both infections because they might have been infected with either virus.

\section{Zika Virus Infection and Immune Response}

Most Zika virus infections are asymptomatic (12). Viremia is expected to occur from several days before illness onset until a week after illness onset $(6,13,14)$. Zika virus-specific IgM antibodies develop during the first week of illness $(5,6)$. Data on duration of IgM antibody persistence following Zika virus infection are limited. However, IgM antibodies against West Nile virus, a closely related flavivirus, have been detected in asymptomatic, infected blood donors for at least 3 months after their viremic donation, and almost half of tested patients with West Nile virus neuroinvasive disease had detectable serum $\operatorname{IgM}$ antibodies $>1$ year after illness onset $(15,16)$. Neutralizing antibodies to Zika virus develop shortly after IgM antibodies and consist primarily of IgG antibodies. Neutralizing antibodies are expected to persist for many years after flavivirus infections and are believed to confer prolonged, possibly lifelong, immunity (17-19). In persons previously infected with a flavivirus or vaccinated against yellow fever, Japanese encephalitis, or tick-borne encephalitis, subsequent exposure to a related flavivirus can result in a rapid and brisk rise in neutralizing antibodies against multiple flaviviruses (20). In addition, the neutralizing antibody titer against a flavivirus to which the person previously was exposed might be higher than the titer against the virus with which they were most recently infected (20). For example, a person who was previously infected with dengue virus or who received yellow fever vaccine might respond with high levels of neutralizing antibodies against those viruses when later infected with Zika or West Nile viruses. When performing serologic testing, the presence of these neutralizing antibodies against multiple flaviviruses can preclude conclusive determination of which flavivirus was responsible for the recent infection.

\section{Zika Virus Antibody Testing}

An enzyme-linked immunosorbent assay (ELISA) can be used to detect anti-Zika virus IgM antibodies in serum or cerebrospinal fluid; however, the Zika virus IgM ELISA can provide false-positive results because of cross-reacting IgM antibodies against related flaviviruses or nonspecific reactivity. The plaque reduction neutralization test (PRNT) measures virus-specific neutralizing antibody titers and should be performed against various related flaviviruses to rule out false-positive ELISA results. In primary flavivirus infections (i.e., the first time a person is infected with a flavivirus), PRNT also can be used to identify the infecting virus. Usually, this is determined with a neutralizing antibody titer $\geq 4$-fold higher than titers against cross-reacting flaviviruses. Based on earlier flavivirus research and limited preliminary data specific to Zika virus, the historical use of a 4-fold higher titer by PRNT might not discriminate between anti-Zika virus antibodies and cross-reacting antibodies in all persons who have been previously infected with or vaccinated against a related flavivirus (i.e., secondary flavivirus infection) $(20,21)$. Because of the importance of appropriate clinical management of Zika and dengue virus infections, and 
the risk for adverse pregnancy outcomes in women infected with Zika virus during pregnancy, a conservative approach to the interpretation of antibody test results is now recommended to reduce the possibility of missing the diagnosis of either infection $(9,11)$.

\section{CDC Zika Virus Diagnostic Tests}

The Food and Drug Administration (FDA) has issued an Emergency Use Authorization for the CDC Zika IgM Antibody Capture Enzyme-Linked Immunosorbent Assay (Zika MAC-ELISA) for antibody testing (3). This assay has been introduced and is being used in qualified public health and Department of Defense laboratories in the United States. The Zika MAC-ELISA is used for the qualitative detection of Zika virus IgM antibodies in serum or cerebrospinal fluid collected from persons meeting the clinical and epidemiologic criteria for suspected Zika virus disease $(3,22)$. Results are reported as positive (termed "presumptive positive" to denote the need to perform a confirmatory PRNT), equivocal, negative, or inconclusive (i.e., results uninterpretable because of high background optical density). To resolve false-positive results that might be caused by cross-reactivity or nonspecific reactivity, presumptive positive results should be confirmed with PRNT against Zika, dengue, and other flaviviruses to which the person might have been exposed $(3,23)$. In addition, equivocal and inconclusive results that are not resolved by retesting also should have PRNT performed to rule out a false-positive result.

\section{Interpretation of Zika Virus Testing Results}

For persons with suspected Zika virus disease, a positive rRT-PCR result confirms Zika virus infection, and no antibody testing is indicated $(3,4,7)$. However, because of the decline in the level of viremia over time and possible inaccuracy in reporting of dates of illness onset, a negative rRT-PCR result does not exclude Zika virus infection. Therefore, serum IgM antibody testing for Zika and dengue virus infections should be performed if rRT-PCR is negative. For serum specimens collected $<7$ days after onset of symptoms, the combination of a negative rRT-PCR result and negative IgM antibody testing suggests that there was no recent infection. However, a negative IgM antibody test, in the absence of rRT-PCR testing, might reflect specimen collection before development of detectable antibodies and does not rule out infection with the viruses for which testing was performed. For specimens collected from 7 days to 12 weeks after onset of symptoms, a negative IgM antibody result to both Zika and dengue viruses rules out recent infection with either virus.

\section{Summary \\ What is already known about this topic?}

Zika virus is a mosquito-borne flavivirus closely related to dengue, West Nile, Japanese encephalitis, and yellow fever viruses. Diagnostic testing for Zika virus infection can be accomplished using both molecular and serologic methods. However, results of Zika virus antibody testing can be difficult to interpret because of cross-reactivity with related flaviviruses, which can preclude identification of the specific infecting virus, especially when the person previously was infected with or vaccinated against a related flavivirus.

What is added by this report?

For persons with suspected Zika virus disease, a positive real-time reverse transcription-polymerase chain reaction (rRT-PCR) result confirms Zika virus infection, but a negative result does not exclude infection. In these cases, antibody testing can identify additional recent Zika virus infections. If immunoglobulin (lg) M test results are positive, equivocal, or inconclusive, performing a plaque reduction neutralization test (PRNT) is needed to confirm the diagnosis. However, recent evidence suggests that a 4-fold higher titer by PRNT might not discriminate between anti-Zika virus antibodies and crossreacting antibodies in all persons who have been previously infected with or vaccinated against a related flavivirus. Thus, a more conservative approach to interpreting PRNT results is now recommended to reduce the possibility of missing the diagnosis of either Zika or dengue virus infection.

What are the implications for public health practice?

All patients with clinically suspected dengue should receive appropriate management to reduce the risk for hemorrhagic medical complications. Pregnant women with laboratory evidence of a recent Zika virus infection or flavivirus infection should be evaluated and managed for possible adverse pregnancy outcomes and reported to the appropriate Zika virus pregnancy registry. Health care providers should consult with state or local public health authorities for assistance in interpreting test results.

If either the Zika or dengue virus IgM antibody testing yields positive, equivocal, or inconclusive results, PRNTs against Zika and dengue viruses (or other flaviviruses endemic to the region where exposure occurred) should be performed. A PRNT using a $90 \%$ cutoff value with a titer $\geq 10$ (the typical starting serum dilution used to establish the presence of virus-specific neutralizing antibodies) against Zika virus, together with negative PRNTs (i.e., <10) against other flaviviruses is confirmatory for recent infection with Zika virus (Table). A PRNT titer $\geq 10$ for both Zika and dengue virus (or another flavivirus) provides evidence of a recent infection with a flavivirus but precludes identification of the specific infecting virus. A negative PRNT against Zika virus in a specimen that is collected $>7$ days after illness onset rules out Zika virus infection. For specimens collected $<7$ days after onset of symptoms, the combination of a 
Morbidity and Mortality Weekly Report

TABLE. Interpretation of results of antibody testing for suspected Zika virus infection $*,+, \S, \uparrow, * *$ — United States, 2016

\begin{tabular}{|c|c|c|c|}
\hline Zika virus and dengue virus IgM ELISA & $\begin{array}{l}\text { Zika virus } \\
\text { PRNT }\end{array}$ & $\begin{array}{l}\text { Dengue virus } \\
\text { PRNT }\end{array}$ & Interpretation \\
\hline Positive or equivocal (either assay) & $\geq 10$ & $<10$ & Recent Zika virus infection \\
\hline Positive or equivocal (either assay) & $<10$ & $\geq 10$ & Recent dengue virus infection \\
\hline Positive or equivocal (either assay) & $\geq 10$ & $\geq 10$ & Recent flavivirus infection; specific virus cannot be identified \\
\hline $\begin{array}{l}\text { Inconclusive in one assay AND inconclusive or negative } \\
\text { in the other }\end{array}$ & $\geq 10$ & $<10$ & Evidence of Zika virus infection; timing cannot be determined \\
\hline $\begin{array}{l}\text { Inconclusive in one assay AND inconclusive or negative } \\
\text { in the other }\end{array}$ & $<10$ & $\geq 10$ & Evidence of dengue virus infection; timing cannot be determined \\
\hline $\begin{array}{l}\text { Inconclusive in one assay AND inconclusive or negative } \\
\text { in the other }\end{array}$ & $\geq 10$ & $\geq 10$ & $\begin{array}{l}\text { Evidence of flavivirus infection; specific virus and timing } \\
\text { cannot be determined }\end{array}$ \\
\hline Any result (either or both assays) & $<10$ & $<10$ & No evidence of Zika virus or dengue virus infection \\
\hline Positive for Zika virus AND negative for dengue virus & \multicolumn{2}{|c|}{ Not yet performed } & Presumptive recent Zika virus infection \\
\hline Positive for dengue virus AND negative for Zika virus & \multicolumn{2}{|c|}{ Not yet performed } & Presumptive recent dengue virus infection \\
\hline Positive for Zika virus AND positive for dengue virus & \multicolumn{2}{|c|}{ Not yet performed } & Presumptive recent flavivirus virus infection \\
\hline Equivocal (either or both assays) & \multicolumn{2}{|c|}{ Not yet performed } & Equivocal results \\
\hline $\begin{array}{l}\text { Inconclusive in one assay AND inconclusive or negative } \\
\text { in the other }\end{array}$ & \multicolumn{2}{|c|}{ Not yet performed } & Inconclusive results \\
\hline Negative for Zika virus AND negative for dengue virus & \multicolumn{2}{|c|}{ Not indicated } & No evidence of recent Zika virus or dengue virus infection \\
\hline
\end{tabular}

Abbreviations: ELISA = enzyme-linked immunosorbent assay; IgM = immunoglobulin $\mathrm{M}$ antibodies; PRNT = plaque reduction neutralization test.

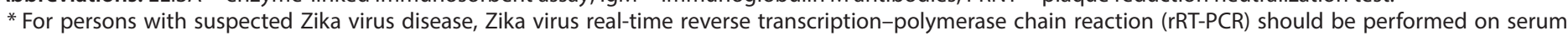
specimens collected $<7$ days after onset of symptoms, and on urine specimens collect $<14$ days after onset of symptoms.

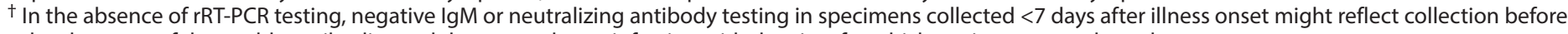
development of detectable antibodies and does not rule out infection with the virus for which testing was conducted.

$\S$ Zika IgM positive result is reported as "presumptive positive" to denote the need to perform confirmatory PRNT.

I Report any positive or equivocal IgM Zika or dengue results to state or local health department.

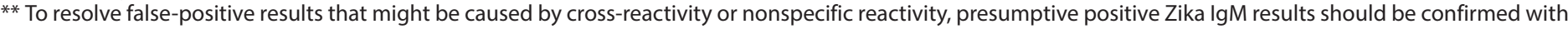

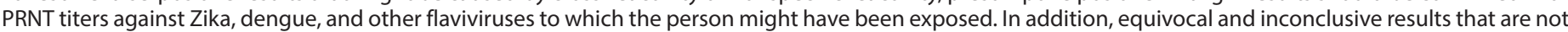
resolved by retesting also should have PRNT titers performed to rule out a false-positive result.

negative rRT-PCR and a PRNT titer $<10$ suggests that there was no infection with Zika virus. However, in the absence of rRT-PCR testing, a PRNT titer $<10$ might reflect specimen collection before development of detectable neutralizing antibodies and does not rule out infection with the viruses for which testing was conducted. Without confirmatory PRNTs, it is not possible to determine whether a presumptive positive IgM antibody result against Zika virus reflects recent flavivirus infection or a false-positive result.

For asymptomatic pregnant women residing in an area with local Zika virus transmission, IgM testing should be performed upon initiation of prenatal care, mid-second trimester, and if any fetal abnormalities are detected during ultrasound evaluation (9). For asymptomatic pregnant women with a history of travel to areas where ongoing Zika virus transmission is occurring, Zika virus antibody testing should be performed on specimens collected 2-12 weeks post travel (9). Results are interpreted as for symptomatic persons. If a serum specimen was collected $>12$ weeks after travel, although IgM might still be present, it is possible that antibody levels have dropped below the detectable limit. Performing routine PRNTs for women in this group is not recommended because any result other than a PRNT titer $<10$ for Zika virus could represent infection with or vaccination against a flavivirus at any time in the past and does not provide specific evidence of Zika virus exposure during pregnancy.

\section{Management of Persons with Suspected Zika or Dengue Virus Infection}

All patients with clinically suspected dengue virus infection should receive appropriate management to reduce the risk for hemorrhagic complications (11). Symptomatic and asymptomatic pregnant women with serologic or molecular evidence of recent Zika virus infection should be evaluated and managed for possible adverse pregnancy outcomes and reported to the U.S. Zika Pregnancy Registry or the Puerto Rico Zika Active Pregnancy Surveillance System (9,10). Among persons for whom serologic testing is unable to determine the most recent infecting flavivirus, an epidemiologic link to a laboratory-confirmed case of dengue or Zika virus disease can be considered in determining the most likely infecting virus (22). In addition, data on the epidemiology of viruses known to be circulating at the location of exposure and clinical features of these viral infections should be considered. If serologic testing is inconclusive or there is evidence of recent infection with either Zika or dengue virus, patients should be clinically managed for both infections because they might have been infected with either virus. Health care providers with questions about test result interpretation should consult with state or local public health authorities for assistance.

\footnotetext{
${ }^{1}$ Zika virus response epidemiology and laboratory teams, CDC.

Corresponding author: Ingrid B. Rabe, irabe@cdc.gov, 970-221-6400.
} 


\section{References}

1. Faye O, Freire CCM, Iamarino A, et al. Molecular evolution of Zika virus during its emergence in the 20th century. PLoS Negl Trop Dis 2014;8:e2636. http://dx.doi.org/10.1371/journal.pntd.0002636

2. Hayes EB. Zika virus outside Africa. Emerg Infect Dis 2009;15:1347-50. http://dx.doi.org/10.3201/eid1509.090442

3. Food and Drug Administration. Zika virus emergency use authorization. Silver Spring, MD: US Department of Health and Human Services, Food and Drug Administration; 2016. http://www.fda.gov/ MedicalDevices/Safety/EmergencySituations/ucm161496.htm

4. CDC. Interim guidance for Zika virus testing of urine-United States, 2016. MMWR Morb Mortal Wkly Rep 2016;65:474. http://dx.doi. org/10.15585/mmwr.mm6518e1

5. Bingham AM, Cone M, Mock V, et al. Comparison of test results for Zika virus RNA in urine, serum, and saliva specimens from persons with travel-associated Zika virus disease-Florida, 2016. MMWR Morb Mortal Wkly Rep 2016;65:475-8. http://dx.doi.org/10.15585/mmwr. $\mathrm{mm} 6518 \mathrm{e} 2$

6. Lanciotti RS, Kosoy OL, Laven JJ, et al. Genetic and serologic properties of Zika virus associated with an epidemic, Yap State, Micronesia, 2007. Emerg Infect Dis 2008;14:1232-9. http://dx.doi.org/10.3201/ eid1408.080287

7. CDC. Revised diagnostic testing for Zika, chikungunya, and dengue viruses in US public health laboratories. http://www.cdc.gov/zika/pdfs/ denvchikvzikv-testing-algorithm.pdf

8. Calisher CH, Karabatsos N, Dalrymple JM, et al. Antigenic relationships between flaviviruses as determined by cross-neutralization tests with polyclonal antisera. J Gen Virol 1989;70:37-43. http://dx.doi. org/10.1099/0022-1317-70-1-37

9. Petersen EE, Polen KND, Meaney-Delman D, et al. Update: interim guidelines for health care providers caring for pregnant women and women of reproductive age with possible Zika virus exposure-United States, 2016. MMWR Morb Mortal Wkly Rep 2016;65:315-22. http:// dx.doi.org/10.15585/mmwr.mm6512e2

10. Simeone RM, Shapiro-Mendoza CK, Meaney-Delman D. Possible Zika virus infection among pregnant women-United States and territories, May 2016. MMWR Morb Mortal Wkly Rep 2016;65:514-9.

11. World Health Organization. Dengue guidelines for diagnosis, treatment, prevention and control, 2009. Geneva, Switzerland: World Health Organization; 2009. http://apps.who.int/iris/bitstream/10665/44188/ 1/9789241547871_eng.pdf
12. Duffy MR, Chen TH, Hancock WT, et al. Zika virus outbreak on Yap Island, Federated States of Micronesia. N Engl J Med 2009;360:2536-43. http://dx.doi.org/10.1056/NEJMoa0805715

13. Musso D, Nhan T, Robin E, et al. Potential for Zika virus transmission through blood transfusion demonstrated during an outbreak in French Polynesia, November 2013 to February 2014. Euro Surveill 2014;19:20761. http://dx.doi.org/10.2807/1560-7917.ES2014.19.14.20761

14. Musso D, Roche C, Nhan TX, Robin E, Teissier A, Cao-Lormeau VM. Detection of Zika virus in saliva. J Clin Virol 2015;68:53-5. http:// dx.doi.org/10.1016/j.jcv.2015.04.021

15. Prince HE, Tobler LH, Yeh C, Gefter N, Custer B, Busch MP. Persistence of West Nile virus-specific antibodies in viremic blood donors. Clin Vaccine Immunol 2007;14:1228-30. http://dx.doi.org/10.1128/ CVI.00233-07

16. Roehrig JT, Nash D, Maldin B, et al. Persistence of virus-reactive serum immunoglobulin M antibody in confirmed West Nile virus encephalitis cases. Emerg Infect Dis 2003;9:376-9. http://dx.doi.org/10.3201/ eid0903.020531

17. Whitehead SS, Blaney JE, Durbin AP, Murphy BR. Prospects for a dengue virus vaccine. Nat Rev Microbiol 2007;5:518-28. http://dx.doi. org/10.1038/nrmicro 1690

18. Busch MP, Kleinman SH, Tobler LH, et al. Virus and antibody dynamics in acute West Nile virus infection. J Infect Dis 2008;198:984-93. http:// dx.doi.org/10.1086/591467

19. Poland JD, Calisher CH, Monath TP, Downs WG, Murphy K. Persistence of neutralizing antibody $30-35$ years after immunization with $17 \mathrm{D}$ yellow fever vaccine. Bull World Health Organ 1981;59:895-900.

20. Halstead SB, Rojanasuphot S, Sangkawibha N. Original antigenic sin in dengue. Am J Trop Med Hyg 1983;32:154-6.

21. Johnson BW, Kosoy O, Martin DA, et al. West Nile virus infection and serologic response among persons previously vaccinated against yellow fever and Japanese encephalitis viruses. Vector Borne Zoonotic Dis 2005;5:137-45.

22. Council of State and Territorial Epidemiologists. Zika virus disease and congenital Zika virus infection interim case definition and addition to the Nationally Notifiable Diseases list. Atlanta, GA: Council of State and Territorial Epidemiologists; 2016. https://www.cste2.org/docs/Zika_ Virus_Disease_and_Congenital_Zika_Virus_Infection_Interim.pdf

23. Martin DA, Muth DA, Brown T, Johnson AJ, Karabatsos N, Roehrig JT. Standardization of immunoglobulin M capture enzyme-linked immunosorbent assays for routine diagnosis of arboviral infections. J Clin Microbiol 2000;38:1823-6. 